\title{
Medical education in times of COVID - 19: an experience at Faculdade Pernambucana da Saúde
}

Gilliatt Hanois Falbo 1

iD https://orcid.org/0000-0003-4618-2084

Carla Adriane Leal de Araújo 2

iD https://orcid.org/0000-0002-0282-2038

Edvaldo da Silva Souza 3

(iD https://orcid.org/0000-0001-7722-4238

1-3 Faculdade Pernambucana de Saúde. Av. Mal. Mascarenhas de Morais, 4861. Imbiribeira. Recife, PE, Brasil. CEP: 51.150-000. E-mail: edvaldo.s@fps.edu.br

\begin{abstract}
Objectives: to describe and discuss interventions and strategies carried out at Faculdade Pernambucana de Saude (FPS) during the COVID-19 pandemic to mitigate impairment in learning and preserve students, tutors, and staff's health.

Experience report: the teaching methodology used by FPS is problem-based learning, which greatly facilitated the non-discontinuity of theoretical activities carried out in-person in tutorial sessions involving a tutor and 10 to 12 students. This format was transferred to Webex Meetings rooms and held remotely. Practical laboratory activities were suspended and resumed when allowed in July. The teaching outpatient activities (third and fourth year) were suspended and resumed in August. Two years of internship were interrupted for 30 days (fifth year) and for 15 days (sixth year). External activities of practices in primary care were also suspended and resumed gradually. All assessments and activities that required face-to-face meetings, integrations, scientific initiation program orientations, collegiate meetings, meetings of the self-assessment committee were and are being carried out remotely.

Conclusions: we believe that we were able to mitigate impairment in students' learning without compromising the conclusion of the school year that was facilitated by Problem Based Learning method.

Palavras-chave Medical education, COVID-19, Problem based learning
\end{abstract}




\section{Introduction}

Faculdade Pernambucana de Saúde (FPS) was accredited through the Ministry of Education (MEC) Ordinance Number 2990 on August 30, 2005, published in the Official Gazette of the Union on September 1, 2005, 1 to offer courses in the health area, counting in 2020 with seven courses: Nursing, Pharmacy, Physiotherapy, Medicine, Nutrition, Dentistry and Psychology, all in face-to-face modality and using Problem Based Learning (PBL) as the methodology. PBL concluded its 50th anniversary in 2019 and originated as a pedagogical experiment at McMaster University School of Medicine, in Canada. In the following decades the methodology was improved and used in several higher education courses around the world. ${ }^{2}$ It is characterized as a method in which real-world problems are used to promote the learning of concepts and principles and allowing the development of skills such as: critical thinking, problem solving, and communication. PBL uses, among other active educational strategies, tutorial sessions for the presentation, study and discussion of problems in place of traditional lectures. 3

1.Characteristics of FPS Medical School.

The medical course at FPS is developed face-toface with 8,710 hours and six years minimum and maximum 9 years of schooling. The theoretical activities and skill laboratories take place on the FPS Campus and the activities in practice settings are developed at the Sistema Único de Saúde (SUS) (Public Health System), having the Instituto de Medicina Integral Prof. Fenando Figueira (IMIP) as a teaching hospital. The educational activities are briefly described below:

- In the $1^{\text {st }}$ and $2^{\text {nd }}$ years:the modules (subjects) are worked in tutorial form (groups of ten to 12 students); the modules of theoretical-practical content are worked in different laboratories and practices on primary care (PPC)with external activities in the Family Health Strategy (FHS);

- In the 3 rd and 4 th years: the modules (subjects) are worked in tutorial form; the modules of theoretical-practical content are worked in the outpatient teaching ambulatories in the areas of Pediatrics, Gynecology and Obstetrics, Internal Medicine, Surgery, Mental Health and Emergencies, these activities are carried out at IMIP and PPC with external activities in theFHSunits;

- In the $5^{\text {th }}$ and $6^{\text {th }}$ years: supervised internship in Pediatrics, Gynecology and Obstetrics, Internal Medicine, Surgery, Public Health and Mental Health at IMIP, and at other teaching hospitals as agreed along with the State and Municipal Health
Secretaries of Pernambuco, and PPC in the FHS units. The theoretical content of the internship, which totals 460 hours, is worked in tutorial form once a week, in addition to scientific meetings of each scenario and rotation. The total workload of the internship is 4,300 hours.

All the theoretical part of the undergraduate course is carried out through tutorial sessions involving one faculty member (tutor) and ten to twelve students. First-time students are randomized into two classes (class 1 - Mondays and Thursdays; class 2 - Tuesdays and Fridays) and second-time students into a single class. This semester we have ten classes in progress, totaling 72 tutorial groups.

2. Facts that preceded the pandemic and contributed to make it easier to overcome the challenges.

There was a concern from the academic management about the mismatch between technological competences among tutors and students. Almost all of our tutors were composed of Baby Boomers (born between 1946 and 1964, unhappy with the innovation that leads to increased workloads) and Generation X (born between 1965 and 1980, they like and interact with the new), and some of Generation Y or Millennials (born between 1981 and 1996 and are more committed to collectivity). While almost all of our students are Generation Z (born between 1997 and 2012, they have more affinity with technology). 4

The intention of reducing this gap led us to a visit in Silicon Valley (California, USA) in October 2018, where among other large technology companies we visited such as CISCO and Stanford University in Palo Alto (California, USA) was to observe the technological advances that could, within our reality, assist in the training of teaching tutors in this area.

To do so, we acquired a Cisco Webex plan, which includes the use of the following tools:

- Teams: which allows the exchange of individual or group messages, two-way digital whiteboard, file sharing and video calling;

- Meetings: which allows real-time video conferencing, audio-only conferencing, screen sharing, and access from any device.

We have built in our Tutor Development Committee- TDC, a digital training project for all our tutorsto start with the digital curation module at the beginning of the second semester of 2019. The next modules under development are: Computational Thinking, Digital Citizenship, and Steam (platform for games and apps). 


\section{Experience Report}

\section{Strategies for coping with the suspension of} classes at FPS

In order to comply with the Ministry of Health number 343 on March 17th, 2020, which provides for the substitution of presential classes by digital classes during the New Coronavirus pandemic situation - COVID-195; amended by the document number 345/20206, FPS through its Teaching, Research and Extension Council (CONEPE), supported by the course and the Structured Teaching Center, decided on the following strategies.

1.1 Tutorial Sessions

When the first cases of COVID-19 occurred in Recife, the State Government informed, through the Decree \#48809 on 03/14/20207, among several measures, that classes would be suspended from March 18th on. In anticipation of the beginning of the Contingency Plan, we opted to suspend tutorial activities on March 16th and 17th, and to carry out the training for the tutors and students by using Webex Meetings, in substitution of face-to-face tutorial group sessions. The tutorials would be carried out remotely, strictly following the seven steps and all the stages of the PBL methodology.

Thus, since March 19th, all the tutorial activities were carried out remotely and synchronously in the same formats and structure as face-to-face tutorialactivity; following the same methodology with the seven steps of PBL and synthesis with the elaboration of conceptual maps.

At the same time, due to the issuance of MEC guidelines 343 and 345, which allows the use of "theoretical academic activities for online activities, using information and communication technologies", this strategy was implemented in all FPS courses.

To ensure the success of this strategy, the logistics of the institution's technology and information team was used, which were responsible for the implementation and follow-up of the support on this demand. A team was made available on a $24 / 7$ call, to support teutors and students in having any possible difficulties to access meeting rooms or using Webex Meetings. In addition, tutorials were also prepared to access and participate in the tutorial sessions made available to all tutors 8 and students. ${ }^{9}$

1.2 Laboratories from 1 st to $2^{\text {nd }}$ year

From the 1 st to the 2nd year, theoretical and practical activities are performed in five laboratories: anatomy, procedures, study of macro and microscopic images of organs and tissues, clinical examination, and communication. In all, there are 24 labo- ratorial activities per week. All the theoretical content of the laboratories was advanced and offered remotely and synchronously, in the same format as the tutorial sessions, including monitors assisting tutors and students. However, because of MEC regulations it did not allow the substitution of practical or laboratorial activities become remotely, all practical and procedural laboratorial content were scheduled to be performed after the permission of returning on-campus activities.

1.3 Outpatient Clinics at the 3 rd and 4 th year Teaching Hospital

All outpatient activities were suspended at IMIP, and therefore the teaching outpatient clinics were also suspended. All workload would be replaced when the outpatient activities were resumed.

1.4 Anticipation of vacation

The academic vacation of the first four years of the course, which takes place in the month of July, was anticipated to the month of May.

1.5 Practice in Primary Care

The PPC activities at the FHS units from the 1st to the 4 th year were suspended. However, the theoretical content performed in-person at FPS Campus in the team-based learning format was performed remotely, in the same format as the tutorial.

1.6 Supervised internship at the Teaching Hospital

As IMIP became a reference for COVID-19, initially (in the month of March), students were removed from the urgency and emergency practice scenarios and redistributed to other hospital practice scenarios. 10 In April, the practice scenarios, in wards, were reduced due to the necessity of offering more beds for COVID patients. At that time, the strategy used was to offer the internship activities on a rotating scale of one to two weeks to avoid unnecessary crowding and risk of bidirectional infection. However, this situation worsened in May, when it was decided to anticipate the residency vacation (one month) and to suspend its activities from June 1 st, 2020.

Theoretical internship activities (tutorial) have been replaced by synchronous remote form and the participation of all interns in the activities of each area (e.g. seminars, case discussions, clinical meetings, journal club, among others) were encouraged.

The 5th to $6^{\text {th }}$ year PPC activities, which included settings such as FHS and Home Care Service, were maintained until vacation time, when they were suspended and resumed in August.

1.7 Integration

Activity that integrates all periods of the medical course to discuss topics related to ethics, self-care, 
environmental health, human rights, education in ethnic-racial relations, and Afro-Brazilian and indigenous culture, which were previously held inperson in a large auditorium, was performed remotely and allowing integration with students and tutors from other courses. For this, the WebexEvents tool was used, which allowed the participation of up to 3,000 people in a single event.

1.8 Summative Evaluation

All summative evaluations of theoretical content of the tutorials and theoretical PPC were replaced by remote evaluations and were made available through the Moodle platform already being used by students and tutors, performing a tutorial and a pilot test available for all the students. 11

Conducting tutorial activities in an online format required new strategies and a reorganization of the assessment process. The strategies include: evaluation of the student by the tutor at each virtual meeting; evaluation of the tutorial group dynamics; self-assessment; evaluation through written tests and feedback.

In relation to the tests for evaluation of the theoretical activities, the tests were prepared using the "Moodle's questionnaire" tool, which has different features about question formats, test configuration to display questions and distracters randomly, automatic display of right and wrong answers at the end of the test, definition of execution time, and among others. The tests were designed by respective tutors, for each period, with multiple choice questions (MCQ) and "open questions" (short answer/short essay) according to the module, based on the proposed learning objectives. The time for each question was three minutes. In the beginning, the question time, the impossibility of reviewing questions and choosing which ones to answer generated different degrees of anxiety among the students. However, collegial meetings with class representatives and FPS assessment coordination minimized this problem.

Still on the evaluation, FPS uses as a formative evaluation every semester, the progress test, which is designed to assess the level of knowledge at the end of the course and is applied for all students in every period of the course. 12 In the first semester of 2020, it would be held on May 13th. However, due to the anticipation of the vacation for the month of May, the test was rescheduled for June 3rd, when academic activities resumed. This test is held in partnership with the Unichristus University, located in Fortaleza-CE. Instead of 120 questions in the printed version, for the online version, this number was reduced to 90 questions and offered in two blocks with 45 questions, with a half hour break between question blocks. The test was conducted with the simultaneous participation of 1030 students $(97 \%$ adhe-rence).

The self-assessment commission held meetings remotely and conducted a survey evaluating the opinion and well-being of FPS community.

1.9 Entrance Exam for the class of 2020.2

An Entrance exam was held in July with the selection process according to the candidates' ENEM score. The candidates could choose the highest score of the exams from the years 2017,2018 or 2019. It was the most competitive entrance exam we have had in the 15 years of FPS.

\section{Other support resources for remote activi-} ties

It is necessary to point out some departments, sectors and services that already exist at FPS, which had a fundamental participation in the strategies and activities implemented during the suspension of classes and social isolation. Among them, we can mention:

- IT Support - need to elaborate an on-call schedule to clarify doubts and technological support for tutors and students;

- The sector of technologies applied for education produced, since the beginning of the pandemic and suspended classroom activities, 26 videos and five podcasts;

- The marketing sector developed eight videos including communications from the board to the students and families, as well as to its employees;

- Library - improvement and availability of online book platforms and replacement of "My Library" with a larger collection for the health area;

- Digital Resources Lab - made available a digital curatorship course and together with the Library produced the e-book entitled "Active Isolation: let's see new possibilities?" with information on readings, movies, exercises for the mind, skills development, relaxation techniques, museum visits, and drawings for coloring 13 ;

- Psycho-pedagogical support-A 24-hour psychological service was offered to tutors, students, and administrative staff. The activities offered have been expanded and extended to tutors and other collaborators as well;

- Social Assistance - There was a greater demand and a need to extend the assistance, not only for students, but also for the parents and employees. All the FPS sectors continued with home-office support;

- Extension Activities - all the projects carried out the Digital Curatorship, making their content 
available weekly, from the definition and reporting experiences. According to the extension project, some migrated their face-to-face activities to remote ones, such as the Cine Club and the Student Mentor;

- Scientific initiation program - all in-person data collection activities were suspended and online collection was maintained. The orientation meetings were held remotely;

- All maintenance, cleaning and security staff received continuous training according to the implementation of the various phases of the pandemic and related to the Campus.

3. Replacement of theoretical and practical activities in laboratories and practices in primary care

With the state decree allowing the return of theoretical and practical activities of the higher education institutions in the state of Pernambuco as of August 13th, we put into practice the plan to return to face-to-face activities by hiring a consulting company in infectology, Superare, coordinated by Dr. Gabriel Serrano. The consultancy validated actions and initiatives of our plan and made recommendations on what personal protective equipment (PPE) we should offer to the students, tutors and staff according to the specifics of each practice scenario, in addition to the use of an application, ASalvus, to monitor the health of the entire FPS community in relation to the infection caused by the new coronavirus. In addition to the app, a monitoring committee was created that includes a nurse with experience in epidemiological surveillance since the beginning of the new coronavirus pandemic. All these strategies supported FPS protocol for the return of the theoretical and practical classroom activities.

All teaching, administrative, support, cleaning, and maintenance staff were trained from August 20th to the $24^{\text {th }}$, and the procedures for returning to theoretical and practical activities started on August 27th, with orientation, distribution of PPE, and recommended sanitary measures, including social withdrawal. To meet the social withdrawal, all laboratory scenarios were "duplicated" by replicating the physical structure in exhibition rooms that we use for meetings.

The almost immediate switch from in-person to remote theoretical activities was only possible due to the fact that FPS already had a Webex license, with tutors already using it since 2019 and a well-trained technological support team. This allowed us to conclude the curricular program for the first semester and not delay the beginning of the second semester program.

The suspension of classroom activities in the first and second year in laboratories was essential to preserve the health of the students, tutors, and staff. With the permission in returning in July, a replacement calendar was drawn up. The offer PPE, social isolation and hygiene norms, and infectious disease consultancy, validating all the measures employed, allowed the Campus to resume operations calmly and safely.

The suspension of practical activities at IMIP (teaching hospital) the outpatient clinics followed the local recommendations to suspend elective care and in order to preserve the health of the students, preceptors, and employees. The return of the outpatient activities at IMIP occurred in late August, gradually, offering PPE, reduction in the number of students per room, and a new rotation schedule. For the third year, the replacement workload for the first semester and completion of the second semester program should come in January 2021 during the vacation period. For the fourth year, priority was given to alternate workload replacement, followed by the second semester schedule, allowing both semesters to be completed in January 2021.

Practical primary care activities were suspended in the six years of the course. This measure was due to both the concern in preserving the health of the students, preceptors, and employees, and also the suspension of activities in some scenarios of the healthcare network. The activities are expected to resume at the end of August.

Regarding to the internship, the withdrawal of students from the gateway scenarios and management of patients with suspected or confirmed infections has changed the entire internship rotation schedule carried out in the four major areas. The rotations that most needed to be reformulated with a gradual decrease of available non-COVID scenarios were the pediatrics and gynecology-obstetrics rotations. The clinical medicine rotation soon followed the same logic, and the surgery rotation was well affected due to the suspension of elective surgeries. We tried to study the epidemiological situation of the pandemic and IMIP scenarios weekly to evaluate the appropriate moment to suspend the activities, neither early nor late.

The integration activities, which were held by each course separately and required the availability of an auditorium with large seating capacity, began to be held remotely, allowing a real integration of students and tutors from FPS health courses. Another advantage was that they could be held at an alternative time to the weekly daily shifts. This method of 
offering integration should remain even after the full face-to-face return is allowed.

The substitution of face-to-face summative evaluations (written tests) required greater technological and technical support and a lot of teamwork. It took a while to be accepted and understood by the students, both regarding the new format, the time limitation (three minutes per question) and the impossibility of reading all the questions, choosing the preferred answer option initially. A formative evaluation will also be carried out in the second semester of 2020 and for 2021.1 the implementation of the remote test with open book (test with consultation of sources). 14 The progress test, which was offered at the same time for approximately 1,100 students from the six years of the medical course, requiring logistics, infrastructure, staff support, and printing of tests, proved feasible to be carried out remotely.

All these strategies to change in such a short period of time, which were implemented in a satisfactory way, only became possible due to the

\section{References}

1. Servant-Miklos VFC, Woods NN, Dolmans DHJM Celebrating 50 years of problem-based learning: progress, pitfalls and possibilities. Adv Health Sci Educ Theory Pract. 2019; 24 (5): 849-51.

2. Schmidt HG, Rotgans JI, Yew EH. The process of problembased learning: what works and why. Med Educ. 2011; 45 (8): 792-806.

3. Brasil. Ministério da Educação. Portaria no. 2.990, de 30 de agosto de 2005. Autoriza o Curso de Medicina da Faculdade Pernambucana de Saúde. DOU 01 set 2005; Seção 1.

4. Michael Dimock. Defining generations: where Millennials end and Generation $\mathrm{Z}$ begins. Pew Research Center FactTank; 2019. Disponível em: https:/www.pewresearch.org/fact-tank/2019/01/17/where-millennials-endand-generation-z-begins/

5. Brasil. Ministério da Educação. Portaria no. 343, de 17 de março de 2020. Dispõe sobre a substituição das aulas presenciais por aulas em meios digitais enquanto durar a situação de pandemia do Novo Coronavírus - COVID-19. DOU 18 mar 2020; Seção 1 .

6. Brasil. Ministério da Educação. Portaria no. 345, de 19 de março de 2020. Altera a Portaria MEC n ${ }^{\circ} 343$, de 17 de março de 2020. DOU 19 mar 2020; Seção 1.

7. Pernambuco. Decreto n. ${ }^{\circ} 48.809$, de 14 de março de 2020 Regulamenta, no Estado de Pernambuco, medidas temporárias para enfrentamento da emergência de saúde engagement of everyone who makes FPS. The pandemic and the demands made us stronger and more united.

\section{Conclusions}

In conclusion, always in accordance with the regulations and legislation in force, FPS managed, remotely, to keep the theoretical activities with quality, trying to minimize losses in learning and keeping the health prevention of FPS community extended to all the practice scenarios. All this was facilitated by PBL methodology used by FPS since its creation.

\section{Authors' Contributions}

All authors collaborated in the preparation and review of the experience report and approved the final version of the article. pública de importância internacional decorrente do coronavírus, conforme previsto na Lei Federal $n^{\circ} 13.979$, de 6 de fevereiro de 2020. Diário Oficial do Estado - PE. 14 mar 2020.

8. Tutorial webex meeting docentes. Recife: Faculdade Pernambucana de Saúde; 2020. Disponível em: https://vimeo.com/397952576

9. Tutorial webex meeting estudantes. Recife: Faculdade Pernambucana de Saúde; 2020. Disponível em: https://vimeo.com/398369159

10. Comunicado Internato. Recife: Faculdade Pernambucana de Saúde; 2020. Disponível em: https://vimeo.com/398249549

11. Tutorial para avaliação on-line. Recife: Faculdade Pernambucana de Saúde; 2020. Disponível em: https://vimeo.com/405778291

12. van der Vleuten CPM, Verwijnen GM, Wijnen WHFW. Fifteen years of experience with progress testing in a problem-based learning curriculum. Med Teach. 1996; 18 (2): 103-10.

13. Repositório digital da FPS. Recife: Faculdade Pernambucana de Saúde; 2020. Disponível em: http://repositorio.fps.edu.br/handle/4861/312.

14. Eurboonyanun C, Wittayapairoch J, Aphinives P, Petrusa E, Gee DW, Phitayakorn R. Adaptation to Open-Book Online Examination During the COVID-19 Pandemic. J Surg Educ. 2020; (20)30346-9:S1931-7204.

Received on September 25, 2020

Approved on December 30, 2020 